\title{
RESULTS OF THERMAL CREEP TEST ON HIGHLY IRRADIATED ZIRLO
}

\author{
M. QUECEDO", M. LLORET, J. M. CONDE ${ }^{1}$, C. ALEJANO'1, J.A. GAGO² and F.J. FERNÁNDEZ ${ }^{2}$ \\ ENUSA Industrias Avanzadas SA, Santiago Rusiñol 12, Madrid, Spain \\ ${ }^{1}$ Consejo de Seguridad Nuclear, Justo Dorado 11, Madrid, Spain \\ ${ }^{2}$ ENRESA, Emilio Vargas 7, Madrid, Spain \\ "Corresponding author. E-mail : MQG@enusa.es
}

Received January 8, 2009

Accepted for Publication January 26, 2009

This paper presents a thermal creep test under internal pressure and post-test characterization performed on high burnup (68 MWd/kgU) ZIRLO. This research has been done by the CSN, ENRESA, and ENUSA in order to investigate the behavior of advanced cladding materials in contemporary PWRs at higher burnup under dry cask storage conditions. Also, to investigate the hydride reorientation, the cool-down of the samples after the test has been done in a coordinated manner with the internal pressure. The creep results obtained are consistent with the expected behavior from reference CWSR material, $\mathrm{Zr}-4$. During the test, the material retained significant ductility: one specimen leaked during the test at an engineering strain of the tube section of $17 \%$; remarkably, the crack closed due to de-pressurization. Although significant hydride reorientation occurred during the cool-down under pressure, no specimen failed during the cool-down.

KEYWORDS : Spent Fuel, ZIRLO, Thermal Creep, High Burnup, Hydride Reorientation, Failure Mechanism

\section{INTRODUCTION}

The strategy followed in Spain for the spent fuel management, except for a limited amount of fuel that was reprocessed in the past, is the open cycle [1]. As for other countries, deep geological disposal is the preferred final solution and for Spanish spent fuel a number of actions have already been undertaken in these regards. However, the final decision has been postponed and due to the limited capacity of some of Nuclear Power Plants, NPP, spent fuel pools and also the decommission of the ZORITA NPP, interim storage at the site of the discharged fuel assemblies in dry conditions has already been initiated. As the capacity of the spent fuel pools for the other NPP will be exhausted in the coming years, the current plan is to build a centralized dry spent fuel and high level waste interim storage facility (the ATC installation), which will be complemented as needed, depending on the final date it will become available, with the necessary dry storage capacity at the NPPs site.

The storage of fuel in dry conditions changes the loading on the fuel from that which exists during the inreactor operation. Upon discharge from the reactor, at atmospheric and lower temperature conditions, the fuel rod cladding experiences tensile hoop stress because of the rod internal pressure. This rod internal pressure is larger than that of the as-manufactured rods due to the release of gaseous fission products and the reduction of the internal void volume for gas accommodation that occurred during irradiation. This pressure difference becomes even higher during the preparation of the fuel for dry storage.

More specifically, the fuel drying operation used to ensure an inert atmosphere in the cask during storage, especially if vacuum drying techniques are used, can elevate the cladding temperature to values close to, or beyond, $400^{\circ} \mathrm{C}$ for periods of tens of hours. The high cladding temperatures will increase the cladding tensile loading due to the increment in rod internal pressure, partially dissolve the in-reactor acquired hydrogen from the cladding and, finally, may trigger a number of degradation mechanisms. Following helium-filling of the cask, the cladding temperature decreases slowly with time as the heat from the fuel is removed by conduction to the cask surface and the decay-heat level decreases.

Considering the elevated cladding temperatures and stresses that may be achieved, thermal creep of the cladding is an important consideration in assessing the fuel rod integrity during its dry storage. Thus, this problem has been actively investigated [2-7] and considered in the operational limits established for the transportation and storage of spent fuel $[8,9]$.

However, there is a limited amount of data available on the thermal creep of the advanced cladding alloys that 
are used in the fuel designs loaded nowadays in PWRs. Besides, as the discharge burnup of the fuel assemblies continues to increase, extending the database to higher burnup is increasingly important. Therefore, the Spanish organizations CSN, ENRESA and ENUSA have carried out a test program to characterize the behavior of spent fuel under dry storage conditions [10,11]. This program is focused on the determination of the isotopic [12] composition and the properties of higher burnup (>45 $\mathrm{MWd} / \mathrm{kgU}$ ) modern fuel cladding. As part of this effort, the most widely used in Spanish PWRs' cladding material, ZIRLO, irradiated up to a high burnup of $68 \mathrm{MWd} / \mathrm{kgU}$ rod average, has been characterized by a number of thermal creep tests and post-test examinations.

\section{TEST MATERIALS}

The tested material was obtained from a $17 \times 17(9.5$ mm outer diameter) fuel rod manufactured by ENUSA using ZIRLO clad in Cold Work Stress Relieved Annealed condition, CWSR. This fuel rod was irradiated in the Vandellós II NPP in a joint Spanish (ENDESA, ENUSA)/ Japanese (KEPCO, Mitsubishi Heavy Industries) research Program. The aim of this program was to characterize the fuel rod performance, including advanced alloys, at higher burnups ( $70 \mathrm{MWd} / \mathrm{kgU})$. Therefore, after completion of the irradiation within the current licensing limits, the rods involved in this program were extracted and reinserted for a fifth cycle of irradiation beyond the licensing limits. To reach the desired target burnup, the burnup extension was performed at a power close to the core average one thus, higher than the typical power for rods at their last cycle of irradiation. Due to the more demanding irradiation conditions used in this program, the achieved oxide thickness on some of the tested specimens $(\sim 120 \mu \mathrm{m})$, and consequently the hydrogen absorbed in the clad ( $~ 800 \mathrm{ppm})$, can be considered as bounding for the fuel to be stored in the future.

The rods involved were fully characterized during manufacturing and during the irradiation by on-site inspections. Once the fifth cycle of irradiation was completed, the rods were extracted from the fuel assembly and shipped to the Studsvik hot cell laboratory for a comprehensive destructive and non-destructive examination. The detailed hot-cell characterization of the cladding can be found in references 13 and 14. In addition, sibling fuel rods were fully characterized in hot cells and used in a number of international programs, such as the Cabri International Program, ALPS and SCIP. Thus, information about the cladding characteristics and mechanical properties before the thermal creep test abound.

From this pre-test information [13] it was concluded that the selected fuel rod ( $\sim 68 \mathrm{MWd} / \mathrm{kgU}$ rod average) was in good condition, with no evidence of loss of oxide integrity, such as oxide spalling, despite the high burnup
Table 1. Conditions of the Thermal Creep Tests

\begin{tabular}{c|c|c|c}
\hline $\begin{array}{c}\text { Test } \\
\text { Identification }\end{array}$ & $\begin{array}{c}\text { Temperature } \\
\left({ }^{\circ} \mathrm{C}\right)\end{array}$ & $\begin{array}{c}\text { Nominal Hoop } \\
\text { Stress (MPa) }\end{array}$ & $\begin{array}{c}\text { Oxide } \\
\text { Thickness }(\mu \mathrm{m})\end{array}$ \\
\hline 1C-I & 360 & 220 & 49 \\
1C-II & 400 & 190 & 60 \\
1C-IV & 380 & 220 & 66 \\
2C-I & 400 & 160 & 102 \\
2C-II & 400 & 190 & 111 \\
2C-III & 400 & 220 & 119 \\
\hline
\end{tabular}

achieved and the severity of the irradiation conditions. As already indicated, the peak waterside oxide thickness was $\sim 120 \mu \mathrm{m}$ and the inner-surface oxide layer on the cladding was $\sim 10 \mu \mathrm{m}$. The corresponding hydrogen content in the cladding measured by vacuum extraction was $\sim 800 \mathrm{ppm}$. As expected for a CWSR material, the hydride orientation was circumferential. Other characteristic high burnup features such as the high burnup structure, tight pellet-to-clad bonding, etc. are observed in these rods. Details can be found in reference 14.

From this rod, three samples, named $1 \mathrm{C}$ in Table 1, were cut just above the mid height fuel rod plane where the neutron fluence and oxide thickness are relatively flat. The other three samples, named $2 \mathrm{C}$ in Table 1, were cut close to the peak oxide thickness.

\section{CREEP TESTS}

\subsection{Test Conditions}

Six thermal creep tests under constant internal pressure were conducted using the ZIRLO rod material. Table 1 summarizes the test conditions for each sample. The 1C-I and 1C-IV tests, performed at the same hoop stress and different temperature, should bring the temperature dependence of the creep while the $2 \mathrm{C}$ series, performed at the same temperature but different stress levels, should provide insights into the stress dependence of the creep. Finally, test 1C-II can be used as a confirmatory test of the dependencies observed in the other tests and to compare the results from two specimens (1C-II and 2C-II) with different oxide thicknesses and hydrogen contents.

First, the test conditions were selected to yield data on secondary creep rates in reasonable test duration while keeping the test temperature limited by the reference value of $400^{\circ} \mathrm{C}$ [8]. Furthermore, the selected conditions allow a direct comparison with some of the results obtained by Tsai et al [6] on the CWSR Zr-4 H.B. Robinson rod with a similar burnup.

All the tests were done in the Studsvik Mechanical 


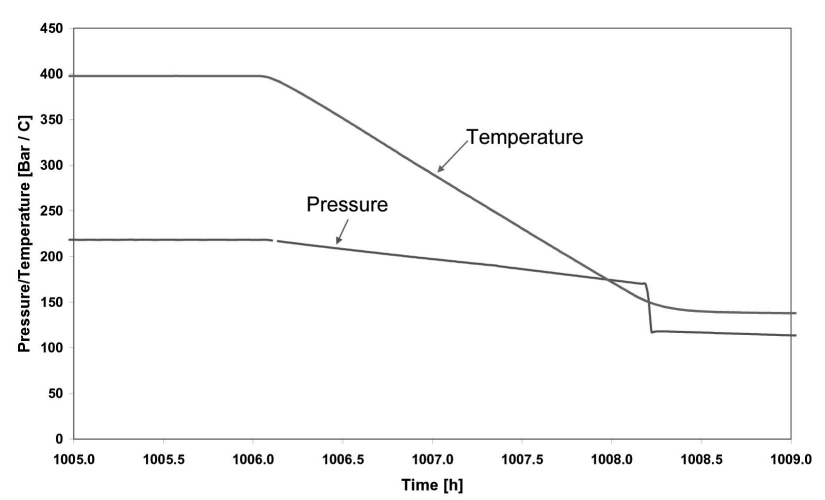

Fig. 1. Example of Creep Test Shutdown Procedure

Laboratory using a pressure-servo controlled system to keep a constant specimen internal pressure. In order to minimize the specimen oxidation at the elevated tests temperatures, Argon was used as pressurizing medium and for the test chamber purge. The internal pressure was specified for each test in order to obtain the desired hoop stress considering the cladding wall thickness reduction due to the in-reactor corrosion layer of each specimen. The pre-test corrosion thickness was obtained from the non-destructive hot cell characterization of the mother rod. The relation between the hoop stress $\sigma_{\theta}$, and the pressure differential is obtained from the thin walled tube equation

$$
\sigma_{\theta}=\frac{\Delta P D_{i}}{2 * w}
$$

where Di is the cladding inside diameter and w the effective wall thickness, i.e. reduced by the metal wastage due to in-reactor corrosion.

In order to study the hydride reorientation, the cooldown of the specimens after the creep tests was specified to be slower than $2^{\circ} \mathrm{C}$ per minute with a coordinated pressure decrease rate representative of the gas content and void volume of a high burnup rod. This procedure is maintained down to a temperature below $150^{\circ} \mathrm{C}$ for which the hydrogen remaining in solid solution can be considered negligible. Figure 1 depicts an example of the shutdown procedure.

Finally, in order to check the potential for a time dependent degradation mechanism, such as Delayed Hydride Cracking, to occur, a holding period at $300^{\circ} \mathrm{C}$ for 48 hours under constant pressure was also included in the shutdown procedure of test $1 \mathrm{C}$-II.

\subsection{Sample Preparation and Test Procedure}

Each sample was cut from the mother rod and refabricated for creep testing following the Studsvik PROVFAB procedure. The total sample length was

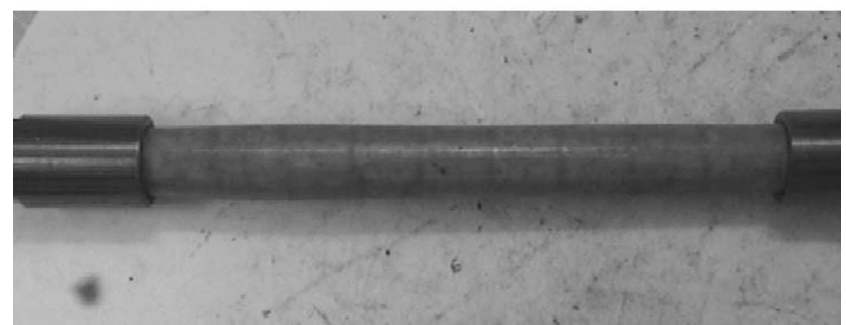

Fig. 2. General Appearance of a Sample Prepared for Creep Testing

selected as a compromise to (i) avoid tube end effects in the measurements, (ii) the extra material needed for a longer sample, and (iii) the homogeneity brought by a shorter sample. Finally, the selected total tube length was $120 \mathrm{~mm}$, resulting in $\sim 90 \mathrm{~mm}$ for the active length.

Once a sample was cut from the rod, mechanically and chemically defueled and inspected, the tube ends needed to be prepared for welding due to the existing corrosion from the in-reactor operation. Besides, welding induces changes in the cladding microstructure and properties making the welding heat affected zone, HAZ, the potential site for strain concentration and specimen failure during the creep test. Therefore, special rigid rings were designed and located at the tube ends to preclude specimen failure at the HAZ. Figure 2 presents the final appearance of the specimens.

The specimens were visually inspected, leak tested, and their profilometry and length recorded.

Before the test starts, the furnace is calibrated to the target temperature using a calibration specimen exactly equivalent (same material and dimensions) to the one to be tested. This calibration specimen is fully instrumented with thermocouples to ensure that the target temperature is achieved with the desired accuracy and to control the axial temperature gradient to the desired value.

Finally, the diameter of the sample is continuously monitored at the control position during the whole test duration using a laser system. The laser control position was located at mid height of the sample at a mid pellet position. Therefore, the full creep strain vs. time, even at the initial stages of the primary creep when the deformation changes very quickly, is available for modeling purposes. Besides, the test interruptions usually needed to perform diameter measurements outside the furnace, with the consequent specimen cool-down and heat-up, are avoided.

After the test, in order to check the potential effects of cladding ovality, four profilometries along the specimen length, i.e one at each $45^{\circ}$ in the azimuthal direction, were done.

\subsection{Test Results}

From the laser readings, the engineering hoop creep strain is calculated as 


$$
\varepsilon_{\theta, \text { creep }}=\frac{D(t, T, P)-D(t=0, T, P)}{D(t=0, \text { Room Conditions })}
$$

Thus, the creep strain is calculated from the diameter increment from that at the test start up, once the temperature and pressure are stabilized. This diameter change is normalized using the diameter before the test, measured at room conditions.

Figure 3 depicts the creep test results. Even though they were cooled down under pressure and relevant hydride reorientation occurred during the cool-down, no specimen failed during the cool-down. Furthermore, one sample, 2C-III, undergoing a large deformation, breached during the test at a peak $17 \%$ strain. Remarkably, the subsequent sample depressurization closed the crack and the specimen remained tight during the cool-down.

All of the samples developed primary and secondary creep; some of them, 2C-II and 2C-III, which were tested under the highest temperature and stress and were selected from the mother rod peak oxide thickness, went into the accelerated creep regime.

Table 2 summarizes the secondary creep rates estimated from the straight portion of the curves. A comparison of these results with the equivalent data from the $\mathrm{Zr}-4$ H.B. Robinson rod [6], with similar burnup and hydrogen

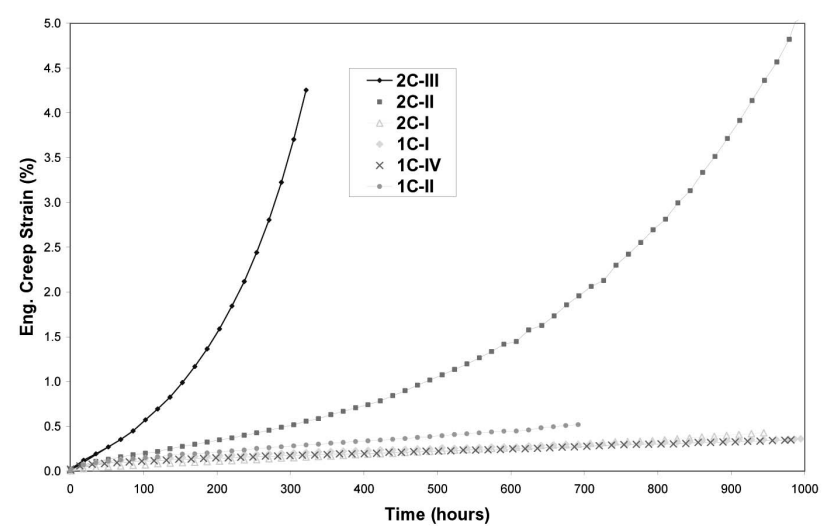

Fig. 3. Creep Test Results

Table 2. Estimated Secondary Creep Rates

\begin{tabular}{c|c}
\hline Test Identification & Secondary Creep Rate (\%/day) \\
\hline 1C-I & 0.0051 \\
1C-II & 0.014 \\
1C-IV & 0.0061 \\
2C-I & 0.0091 \\
2C-II & 0.042 \\
2C-III & 0.107 \\
\hline
\end{tabular}

content as the ZIRLO rod, may suggest similar creep behaviour of Zr-4 and ZIRLO.

The estimated secondary creep rates of $1 \mathrm{C}-\mathrm{I}$ and $1 \mathrm{C}$ IV may suggest a limited dependence on the temperature. Indeed, the ratio of the secondary creep between both tests is $\sim 1.20$, while the calculated ratio for $\mathrm{Zr}-4$ according to Bouffioux [4] is $\sim 3.8$. However, the temperature dependency increases with the test temperature, as indicated by the results of $1 \mathrm{C}$-II.

The stress dependence of ZIRLO seems to be similar to that for $\mathrm{Zr}-4$. Indeed, the ratio of the secondary creep rate between the $2 \mathrm{C}$-II and $2 \mathrm{C}$-I samples is 4.6 , while the calculated ratio [4] is 4.5. A comparison using $2 \mathrm{C}$-III may be more complex as there is a short period of secondary creep and higher uncertainty in the creep rate.

As regards the accelerated creep observed in the two tests, 2C-II and 2C-III, it may be argued that this acceleration is the consequence of the change of the geometry, the increasing tube diameter and reduction of the thickness, which increases the cladding stress. Indeed, considering the large deformations attained, one should use the true strains and stress.

In order to check this possibility, an effort to tune the reference 4 model for $\mathrm{Zr}-4$ to the ZIRLO data has been initiated. For this fitting effort only low strain and primary and secondary creep data have been considered. The tuned model applicability has then been extended by incorporating the true, logarithmic strain and stress to predict the accelerated creep measured data. As the stresses are then continuously changing, the strain hardening rule has been applied with a Newton-Raphson iterative solution for the effective time.

Figure 4 depicts the model predictions and the measured data in test 2C-II: although the feedback effect from the changing geometry can be observed, the model underpredicts the measured data.

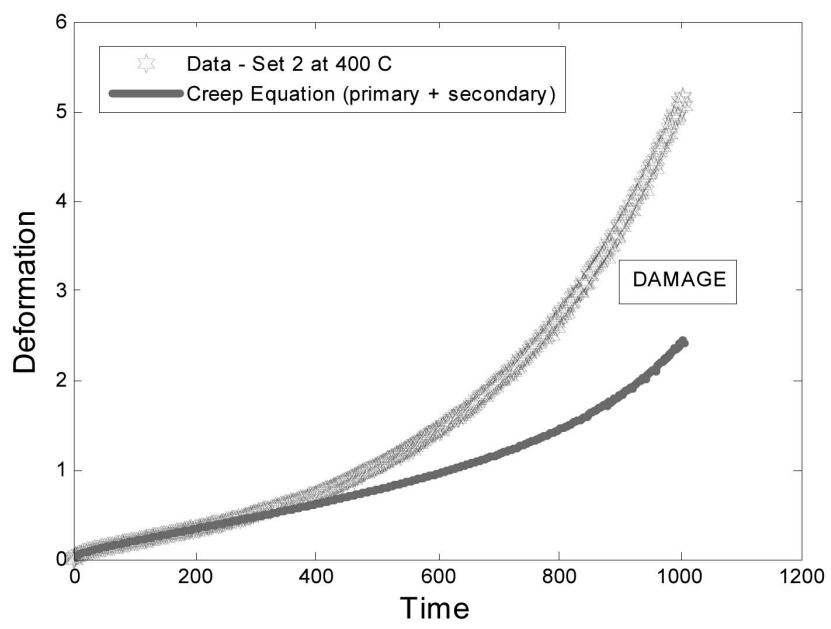

Fig. 4. Model Prediction vs. Measured Data for 2C-II 
Besides, tests $1 \mathrm{C}-\mathrm{II}$ and $2 \mathrm{C}$-II were performed with the same test conditions, but $1 \mathrm{C}$-II does not show any creep acceleration. Therefore, as will be discussed later, another effect should be considered to explain the difference between the measured and predicted values. The analysis of the post-test examinations later on will provide insights into the potential underlying phenomenon.

\section{POST TEST CHARACTERIZATION}

Once the tests were completed, the samples underwent a full characterization. The scope was a visual inspection, profilometry and length measurement, metallographies for hydride morphology and hydrogen content determination, and determination of microhardness.

The pre- and post-test length of each specimens were basically equivalent, within the equipment accuracy and without a trend for the post-test values to be above or below the pre-test one. Therefore, because the deviatoric axial stress component is zero, the coaxiality of the creep rate and deviatoric stress, as typically assumed in creep theories, is verified.

Post-test profilometries along the specimen length were done at each $45^{\circ}$ in the azimuthal direction. The pre-test specimen ovality was minimal, as expected for high burnup samples because the cladding deformation is due to pellet net swelling. The post-test profilometries indicated no discernable effect of the cladding ovality.

Further, from the post-test profilometries, it was determined that there was a relevant difference between the measured strain at the laser position and the peak strain along the sample in tests $2 \mathrm{C}$-II and $2 \mathrm{C}$-III. Indeed, in sample $2 \mathrm{C}$-II the measured engineering strain at the laser position was $5.25 \%$, while the peak was $13.25 \%$; the corresponding values for $2 \mathrm{C}$-III are $5.3 \%$ and $17.3 \%$.
Figure 5 plots the average axial profilometry for test $2 \mathrm{C}$-III.

The corresponding detailed visual inspection of these samples revealed that the peak strain took place at a pelletto pellet interface. Non-penetrating cracks, as presented in Figure 6, were observed at these positions. In the case of test $2 \mathrm{C}$-III, a through-wall crack resulting in a leakage during the test was observed. Thus, metallographies at the peak and laser control position were performed on the different specimens.

Figure 7 presents the metallography at the peak strain position from test $2 \mathrm{C}$-III. There is remarkable cladding ductility as the cracks starting from the thick oxide layer thickness propagate along the brittle hydride rim while the remaining material, with a lower hydrogen content, behaves in a very ductile manner, showing significant necking. Clearly, failure of the specimen took place by shear instability, as seen in Figure 7. Similar features were observed at the laser control position; however, the number of cracks located at the outer cladding diameter, as well as their opening, was much lower in the latter. This observation is consistent with the measured lower deformation of the specimen at the laser control position.

A Scattered Electron Analysis, SEM, of each sample was used in order to measure the local hydrogen content [15] in the azimuthal direction, and its morphology, considering the cool-down under pressure done at the end of the creep test. As the measured hydrogen contents are similar to that measured in the mother rod, there is no evidence of axial migration of hydrogen during the test. This observation is also supported by a previous trial test using a pre-charged sample placed at $400^{\circ} \mathrm{C}$ for fourteen days, demonstrating that there was no discernible axial hydrogen migration to the end plug through the welded area.

Consistent with the existing experience, which indicates that the oxide thickness and hydrogen content are greater at a pellet-to-pellet interface compared to a

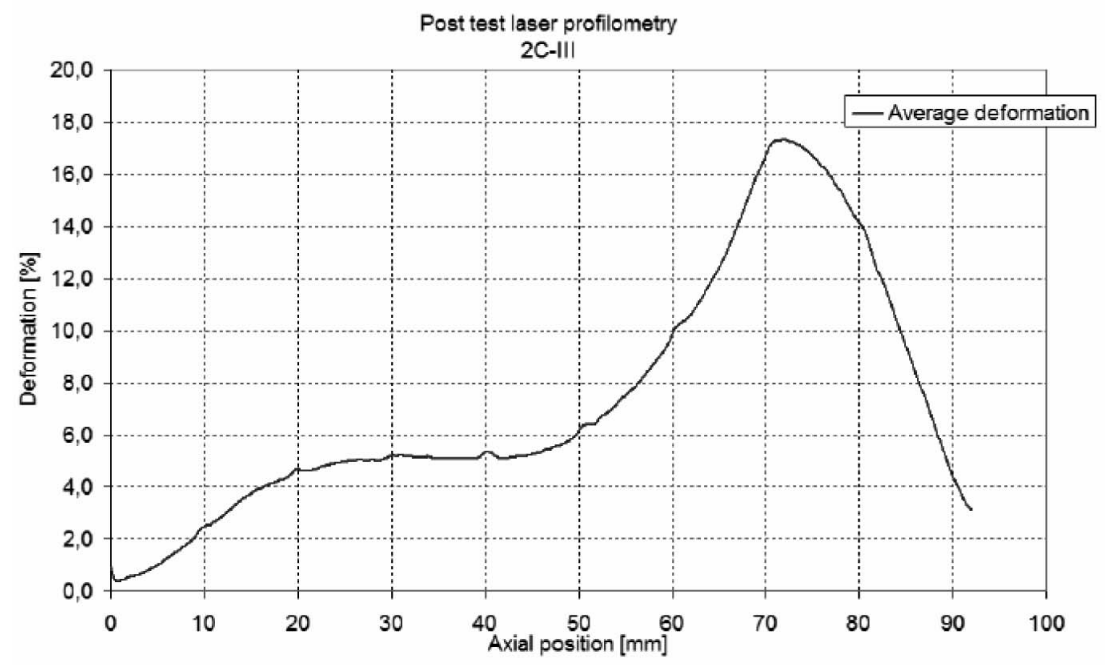

Fig. 5. Post-test Axial Profilometry. Test 2C-III 


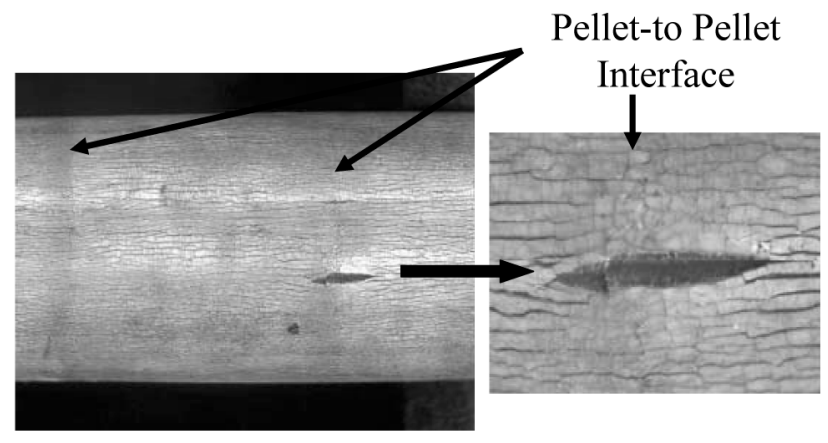

Fig. 6. Non-penetrating Crack Observed at the Peak Strain Location. Test 2C-II

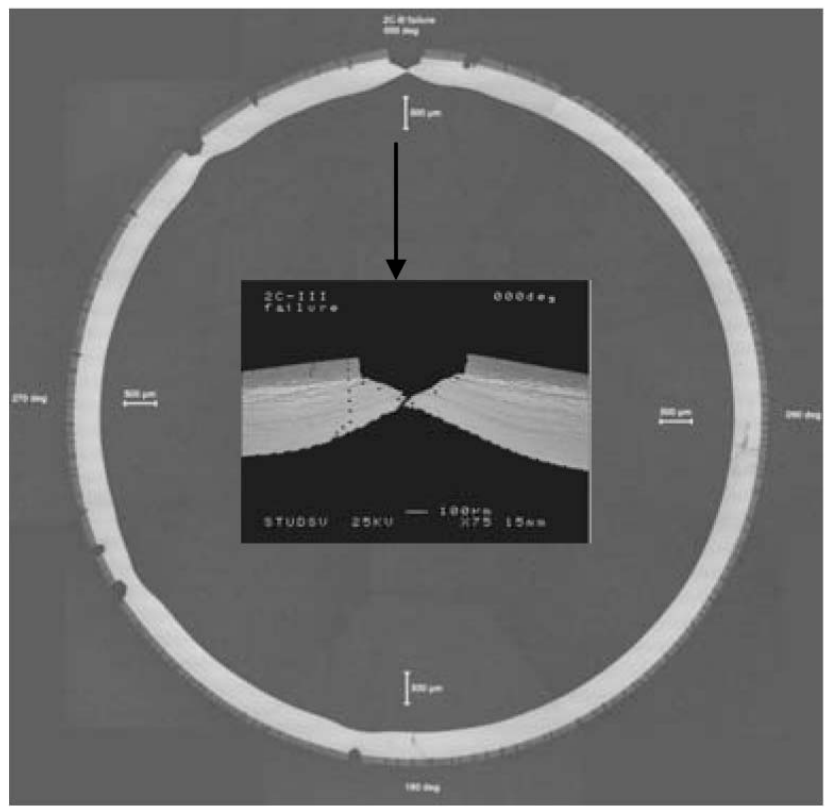

Fig. 7. Metallography at the Peak Strain (17.3\%) Position. Test 2C-III

mid pellet position, the oxide thickness and hydrogen content $(135 \mu \mathrm{m} / 1113 \mathrm{ppm})$ were also higher at the peak strain position (pellet-to-pellet) than at the laser control one (mid pellet). Besides, the penetrating crack occurred at the azimuthal position where the local oxide thickness and hydride rim thickness achieved their maximum values, i.e. the deepest starting crack.

Similar features were observed in the corresponding metallograhies performed in test $2 \mathrm{C}$-II. Figure 8 depicts a backscattered electron image of the main crack, presented in Figure 6, at the peak strain position; we can see the very large crack opening and significant plasticity at the crack tip. Also, significant hydride reorientation occurred at this location. Remarkably, the specimen did not fail even during the cooling-down under pressure.

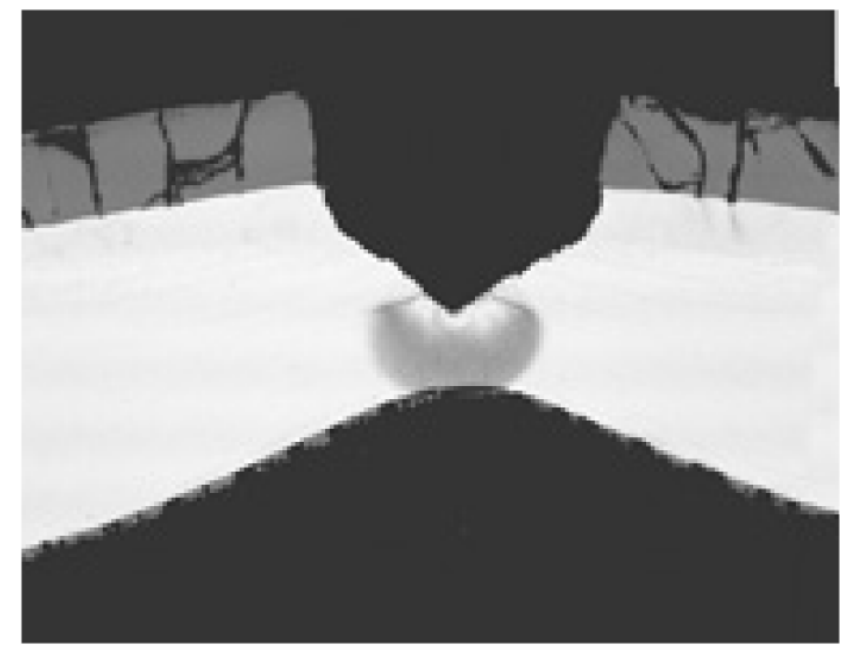

Fig. 8. SEM at the Major Crack Showing the Plastic Hinge at the Crack Tip. Test 2C-II. Tubing Section Average Engineering Strain: $13.25 \%$

In test $2 \mathrm{C}$-II, only one crack propagating through the cladding metal is observed in this section, all deformation is concentrated on this crack as is typical of strain localization. The remaining cracks start at the oxide layer and penetrate just a few microns into the hydride rim.

Finally, the combined effect of the oxide layer and the hydride rim may be the explanation of the larger creep measured in test $2 \mathrm{C}$-II when compared to test 1C-II, even though both tests were performed at the same conditions. Indeed, the estimated section average oxide plus hydride rim thickness is $70 \mu \mathrm{m}$ for $1 \mathrm{C}$-II while for $2 \mathrm{C}$-II it is 120 $\mu \mathrm{m}$. However, as already explained, the oxide thickness was taken into account when setting the test conditions, and different pressurization was used in both tests to get the same cladding stresses. Thus, the analysis of both tests continues.

The test shutdown procedure depicted in Figure 1 was quite successful in precipitating the hydrogen in solid solution in the radial direction. All the samples taken from the different tests showed radial hydrides. Figure 9 presents an example taken from test 2C-I, performed with the minimum hoop stress, $160 \mathrm{MPa}$; Figure 10 shows an example obtained from test $1 \mathrm{C}-\mathrm{I}$, at $220 \mathrm{MPa}$.

Cracking of some radial hydrides, preferentially located at the inner diameter, has been observed in some cases. Although it is believed that this cracking may be attributed to the differential stress along the cladding thickness, further investigation is under way.

For sample 1C-IV, a different cool-down protocol, maintaining the sample under constant pressure at $300^{\circ} \mathrm{C}$, was selected. Indeed, in the Studsvik Cladding Integrity Project, a time dependent failure mechanism has been observed [16] at elevated stresses at $300^{\circ} \mathrm{C}$. Therefore, a more realistic but bounding, in the view of dry storage of 


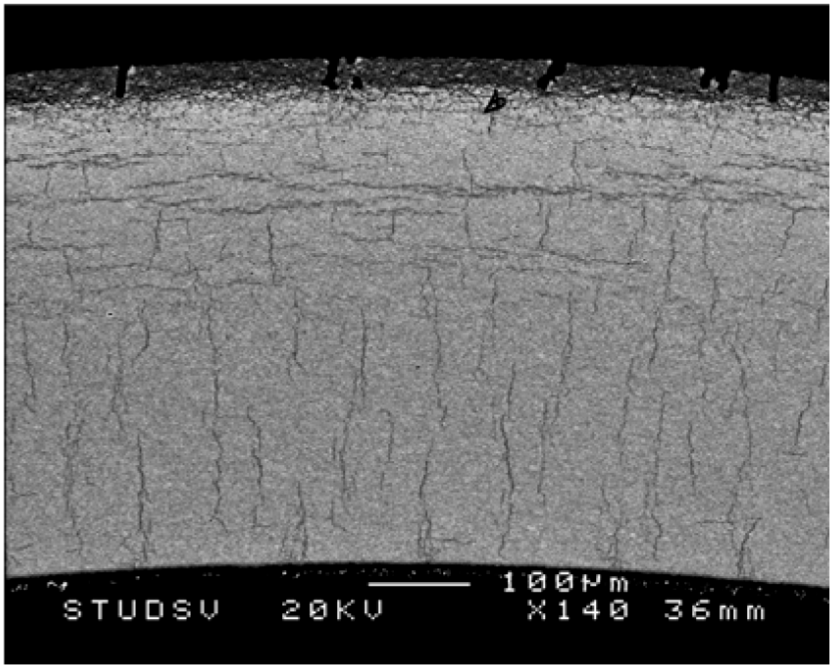

Fig. 9. Hydride Reorientation Due to the Cool-down Under Pressure. Test 2C-I (160 MPa, $\left.400^{\circ} \mathrm{C}\right)$

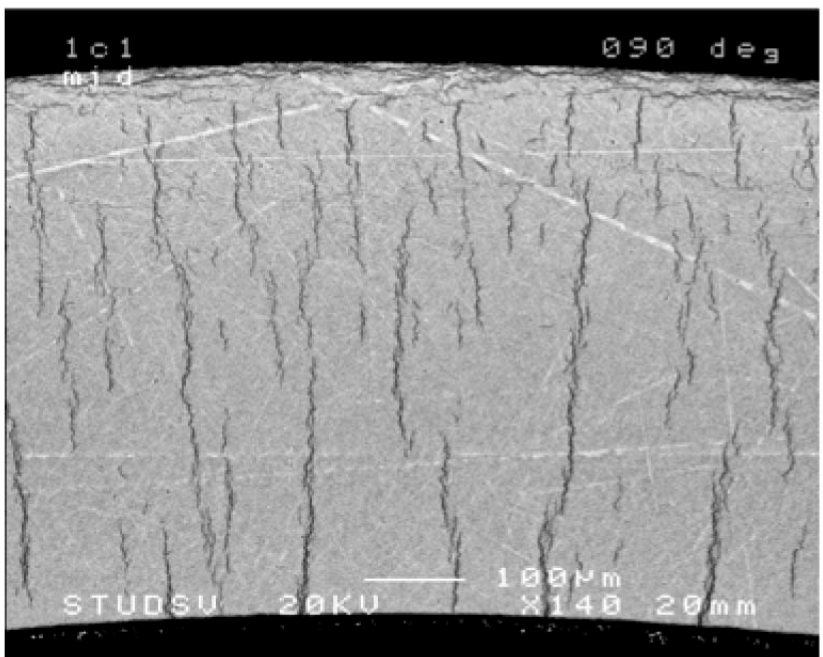

Fig. 10. Hydride Reorientation Due to the Cool-down Under Pressure. Test $1 \mathrm{C}-\mathrm{I}\left(220 \mathrm{MPa}, 360^{\circ} \mathrm{C}\right)$

spent fuel, hoop stress (130 MPa) was selected to keep the sample at $300^{\circ} \mathrm{C}$ for 48 hours. No failure or cladding damage has been observed in the corresponding metallographies although hydride precipitation as radial hydrides has clearly occurred (see Figure 11).

Finally, to check the potential effect of the thermal annealing of the irradiation damage on the observed creep acceleration, a campaign of Vickers microhardness measurement was carried out. Indeed, irradiation damage enhances the creep resistance of the Zirconium alloys and the thermal annealing of the in-reactor irradiation damage during the creep test may override this effect. Therefore, microhardness was selected as an indicator of this potential softening effect.

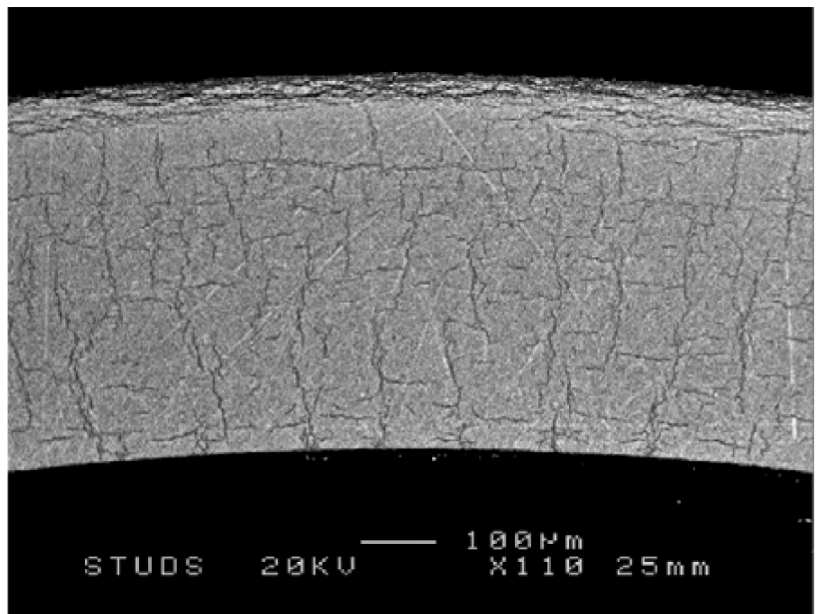

Fig. 11. Radial Hydride Precipitation in Sample 1C-II after Cool Down Including a Temperature Step at Stress

Table 3. Relative through Wall Vickers Microhardness

\begin{tabular}{c|c}
\hline Sample Condition & Relative microhardness \\
\hline Non-irradiated & 1 \\
As irradiated & $1.067-1.113$ \\
$400^{\circ} \mathrm{C} / 330$ hours & $1.046-1.113$ \\
$400^{\circ} \mathrm{C} / 960$ hours & $1.060-1.084$ \\
$360^{\circ} \mathrm{C} / 1000$ hours & $1.06-1.122$ \\
$380^{\circ} \mathrm{C} / 1000$ hours & $1.046-1.070$ \\
\hline
\end{tabular}

This microhardness characterization campaign comprised tested specimens, non-irradiated and postreactor irradiated reference samples. Table 3 summarizes the range of the measured microhardness, relative to nonirradiated material, on samples annealed under different conditions.

The effect of the irradiation hardening is clearly observed by comparing the as-irradiated sample to the fresh, non-irradiated material. Although according to existing research [6], significant annealing should be observed after 72 hours at $420^{\circ} \mathrm{C}$, this effect is not discernible after 330 hours at $400^{\circ} \mathrm{C}$ or an even longer period, 1000 hours, at $380^{\circ} \mathrm{C}$. Therefore, it may be concluded that the performed microhardness evaluation would support the idea that the acceleration on the measured creep is not due to the thermal annealing of the irradiation damage.

\section{CONCLUSIONS}

The CSN, ENRESA and ENUSA have successfully carried out a program to generate thermal creep data on 
high burnup ZIRLO irradiated in the Spanish Vandellós NPP. Six tests under constant internal pressure and a comprehensive pre- and post-test characterization indicate that increasing temperature and stress increases the creep, as was expected. The measured values are also consistent with those expected for a CWSR reference material such as $\mathrm{Zr}-4$.

In order to reorient the precipitating hydrides and to check potential degradation mechanisms, a special procedure for temperature and internal pressure reduction was implemented at the end of each test. Significant radial hydrides precipitated but no failure was observed during this cool-down.

One of the specimens tested under the most demanding conditions, $220 \mathrm{MPa}$ for the hoop stress at $400^{\circ} \mathrm{C}$, leaked during the test. The engineering strain at the failed section was $\sim 17 \%$. This result, along with those from another test, indicates that the material has retained a significant ductility.

Finally, an acceleration of the creep has been observed at the end of some tests. Based on the results from the post-test characterization, this effect is attributed to the strain localization at those crack tips crossing the oxide and hydride rim thickness. As demonstrated by the test result, the crack closes due to de-pressurization.

\section{ACKNOWLEDGMENTS}

The work of Dr. Antonino Romano (ENUSA), who performed the modeling effort of the creep data and considered different continuum damage models, is gratefully recognized.

\section{REFERENCES}

[1] J.E. MARTÍNEZ and J. A. Gago, "An Update on Spent Fuel and HLW Management in Spain" Proc. of the Storage of Spent Fuel from Power Reactors. 2003 Conference, Paper IAEA-CN-102/44, Conference \& Symposium Papers 20/P, IAEA, Vienna (2003).

[2 ] W. GOLL, H. Spilker and E.H. Toscano, "Short-time Creep and Rupture Tests on High Burnup Fuel Rod Cladding" J. Nuc. Mat. 289, 247, (2001).

[ 3 ] C. CAPPELAERE, R. Limon, T. Bredel, P. Herter and D. Gilbon, "Long Term Behavior of the Spent Fuel Cladding in Dry Storage Conditions", Proc. Int. Conf. on Environmental Management, ICEM 2001 Conference, pp. 188-194, Bruges, Oct. 2001.

[4] P. BOUFFIOUX, S. Leclercq, C. Cappelaere and T. Bredel "Interim Dry Storage of PWR Fuel Assemblies-Development of a Long Term Law to Assess the Fuel Rod Cladding
Integrity", Proc. Int. Conf. on Environmental Management, ICEM 2001 Conference, pp. 195-200, Bruges, Oct. 2001.

[5] J. RASHID and A. Machiels, "Creep as the Governing Mechanism of Spent Fuel in Dry Storage", Proc. Int. Conf. on Environmental Management, ICEM 2001 Conference, pp. 201-206, Bruges, Oct. 2001.

[6] H. TSAI and M. Billone, "Thermal Creep of Irradiated Zircaloy Cladding", Journal of ASTM International, Vol. 3, No. 1, Paper ID JAI12425.

[ 7 ] K. ITO, K. Kamimura,Y. Tsukuda, "Evaluation of Irradiation Effect on Spent Fuel Cladding Creep Properties" Proc. of the 2004 Int. Meeting on LWR Fuel Performance, Orlando (Florida), Paper 1117.

[8] US NRC Spent Fuel Office Interim Staff Guidance-11, Revision 3, November 2003.

[9] H. PEEHS, F. Garzarolli, W. Goll, "Assessment of Dry Storage Performance of Spent LWR Fuel Assemblies with Increasing Burnup", in IAEA-TECDOC-1089, pp. 313-324. IAEA, Vienna (1999).

[10] J.M. CONDE, C. Alejano and J.M. Rey, "Nuclear Research Activities of the Consejo de Seguridad Nuclear", Proc. of the 2006 Int. Meeting on LWR Fuel Performance, Salamanca (Spain), p. 107.

[11] J.M. ALONSO, J.M. Conde, J.A. Gago, P. González, M. Novo and L. Herranz, "Spanish R\&D Program on Spent Fuel Dry Storage", Proc. of the 2006 Int. Meeting on LWR Fuel Performance, Salamanca (Spain), p. 213.

[12] H-U. ZWICKY, J. Low, J. Kierkegaard, D. Schrire and M. Quecedo, "Isotopic Analysis of Irradiated Fuel Samples in the Studsvik Hotcell Laboratory", Proc. of the 2004 Int. Meeting on LWR Fuel Performance, Orlando (Florida), Paper 1104.

[13] S. WATANABE, S. Abeta, J.J. Serna, J.M. Alonso, T. Sendo and P. González, "Post irradiation examinations on 67-75 GWd/tU rods for confirmation of the rod integrity and appropriate performance of the claddings for the future", Proc. of the 2005 Water Reactor Fuel Performance Meeting, Kyoto (Japan), Paper 1057.

[14] J.J. SERNA, P. Tolonen, S. Abeta, S. Watanabe, Y. Kosaka, T. Sendo and P. González, "Experimental observations on fuel pellet performance at high burnup", Proc. of the 2005 Water Reactor Fuel Performance Meeting, Kyoto (Japan), Paper 1069.

[15] D. SCHRIRE and J.H. Pearce, "Scanning Electron Microscope Technique for Studying Zircaloy Corrosion and Hydriding", Zirconium in the Nuclear Industry : Tenth Int. Symposium. ASTM STP 1245, pp. 98-115, Philadelphia (1994).

[16] A-M. ALVAREZ-HOLSTON, G. Lysell and V. Grigoriev, "Studies of hydrogen assisted failures initiating at the cladding outer surface of high burn-up fuel using a modified Ring Tensile Technique", Proc. of the 2007 International LWR Fuel Performance Meeting, San Francisco, (California), 2007, Paper 1069. 